\title{
Development of electrically conductive polymer nanocomposites for the automotive cable industry
}

\author{
Miguel Guerreiro ${ }^{1}$ (D), Joana Rompante ${ }^{1}$ (D) André Costa Leite $^{2^{*}}$ (D), Luís Paulo Fernandes ${ }^{2}$ (D), \\ Rosa Maria Santos² (D), Maria Conceição Paiva ${ }^{3}$ (D) and José António Covas ${ }^{3}$ \\ 'Polo de Inovação em Engenharia de Polímeros, Universidade do Minho, Campus de Azurém, \\ Guimarães, Portugal \\ ${ }^{2}$ Companhia de Fios e Cabo, Lda. - Coficab, Guarda, Portugal \\ ${ }^{3}$ Instituto de Polímeros e Compósitos, Universidade do Minho, Campus de Azurém, Guimarães, Portugal \\ * cleiteandre@gmail.com
}

\begin{abstract}
Environmental concerns and the urgent need for reduction of fossil fuel consumption motivate materials research towards increased transportation efficiency. This work investigates the possibility of reducing the weight of electrical cables in automotive applications by replacing part of the metallic screen with electrically conductive polymer/carbon nanotube (CNT) nanocomposites. PP and PA12 were tested as possible matrices and the melt processability of the composites prepared by melt mixing was assessed for compositions up to 4 CNT wt. \%. The tensile and flexural mechanical properties, the electrical conductivity, as well as the electromagnetic shielding effectiveness were evaluated. The performance of PA12/CNT composites was much higher than that of PP/CNT equivalents, due to better dispersion. It was demonstrated that, at industrial production scale, these materials could achieve a reduction of $4-20$ weigth $\%$ relative to a standard automotive cable.
\end{abstract}

Keywords: high voltage cables, carbon nanotubes, nanocomposites, electrical conductivity, wire insulation.

How to cite: Guerreiro, M., Rompante, J., Leite, A. C., Fernandes, L. P., Santos, R. M., Paiva, M. C., \& Covas, J. V. (2021). Development of electrically conductive polymer nanocomposites for the automotive cable industry. Polimeros: Ciência e Tecnologia, 31(2), e2021021. https://doi.org/10.1590/0104-1428.20210017

\section{Introduction}

The automotive industry faces the need to develop new technological solutions to meet increasing societal demands, one of them being the overall reduction of the weight of vehicles ${ }^{[1-3]}$. This is directly related to the optimization of energy efficiency, through the decrease of fuel consumption and the maximization of battery performance, ideally associated with the simplification of manufacturing processes ${ }^{[4-9]}$.

Thermoplastic polymers used at the industrial scale are typically electrical insulators, however their electrical response can be modified by mixing them with electrically conductive materials ${ }^{[10]}$. In this context, the emergence of nanotechnology brought the potential of material modification by incorporation of nanoparticles with specific properties, allowing the development of composites with diverse properties at very low nanoparticle loads ${ }^{[11,12]}$. Some of the solutions explored are based on the use of carbon nanoparticles such as graphene and single-wall (SWCNT) or multi-wall carbon nanotubes (MWCNT), dispersed in a polymeric matrix at a concentration that allows the formation of a percolation network ${ }^{[13-15]}$, producing an electrically conductive nanocomposite ${ }^{[16-19]}$. The advantage of using nanoparticles is the small concentration required to modify the electrical response of the composites from insulating to conductive, the scientific community reporting concentrations ranging from
$0,002 \%$ to $5 \%(\mathrm{w} / \mathrm{w})^{[20-25]}$ depending on the morphology and properties of the CNT, and on the preparation method (the lower concentration range is usually attained when using solution mixing, whilst higher concentrations are required when adopting melt mixing). In order to achieve an electrically conductive polymer composite at a low carbon nanoparticle content, a sufficiently good nanoparticle dispersion and distribution in the polymer is necessary ${ }^{[26-28]}$. Of the different methods that may be used to produce electrically conductive polymer composites, the more advantageous for industrial application is based on melt mixing by co-rotating twin screw extrusion ${ }^{[22,28]}$, as the control of parameters such as residence time and stress levels through proper selection of operating conditions and screw profile allow to obtain good nanoparticle dispersion ${ }^{[27]}$.

Several studies reported the mechanical and electrical properties of nanocomposites containing CNT. For example, the addition of 1,2 and $3 \mathrm{wt} . \%$ of CNT by melt compounding with a polypropylene (PP) copolymer through the dilution of a masterbatch containing 20 wt. $\%$ of CNT, and the comparison with direct compounding of 1, 2 and 3 wt.\% CNT into PP, was investigated ${ }^{[29]}$. An increase in electrical conductivity was obtained by both methods, however due to poorer dispersion of CNT achieved by masterbatch dilution, 
these composites showed comparitively lower conductivity than those produced by direct CNT compounding into the PP matrix. Polyamide 12 (PA12)/CNT composites were produced by melt mixing in a microcompounder, and the influence of parameters such as screw rotation and CNT concentration was studied ${ }^{[30]}$. Optimal volume conductivity was observed at intermediate screw speeds.

The present work investigates the possibility of reducing the weight of a standard high voltage cable used in the automotive industry by replacing the conventional metallic screen with an electrically conductive polymer/ carbon nanotube (CNT) nanocomposite. Polypropylene and polyamide 12 were tested as possible matrices, and compositions of up to 4 weight \% CNT were prepared by melt mixing and characterized, as higher concentrations would compromise the processability. The best performing nanocomposite (based on PA12) was used for the manufacture of cables under industrial conditions, which were subsequently characterized according to the relevant standards. A weight reduction in the range 4 to $20 \%$ was achieved.

\section{Materials and Methods}

\subsection{Materials}

A Polypropylene cable compound (PP) was supplied by Cabopol - Polymer Compounds (Porto de Mós, Portugal), with a melt flow index of $2.5 \mathrm{~g} / 10 \mathrm{~min}^{-1}\left(230{ }^{\circ} \mathrm{C}, 2.16 \mathrm{~kg}\right)$ and a density of $0.9 \mathrm{~g} \mathrm{~cm}^{-3}$. A Polyamide 12 cable compound (PA12) was supplied by Evonik (Essen, Germany), with a melting temperature of $178{ }^{\circ} \mathrm{C}$ and a density of $1.01 \mathrm{~g} \mathrm{~cm}^{-}$ ${ }^{3}$. The MWCNT used as received (i.e., without subsequent functionalization) were NC7000 from Nanocyl, Belgium, characterized by a surface area of 250 to $300 \mathrm{~m}^{2} \mathrm{~g}^{-1}$, average length of $1.5 \mu \mathrm{m}$ and average diameter of $9.5 \mathrm{~nm}$, according to the manufacturer.

\subsection{Composite and sample preparation}

Nanocomposites containing 1, 2, 3 and 4 wt. $\%$ of CNT were prepared with each polymer compound. The PA12 compound was dried at $80{ }^{\circ} \mathrm{C}$ during $8 \mathrm{~h}$ prior to processing. The nanocomposites were prepared by melt mixing using a co-rotating intermeshing twin screw extruder (Coperion ZSK $26 \mathrm{Mc}$ ) with a screw diameter of $25 \mathrm{~mm}$ and a length to diameter ratio (L/D) of 40 . The screws encompassed five mixing zones consisting of kneading disks staggered at 30,45 and $90^{\circ}$, which were separated by conveying zones. The polymers were fed in the main hopper, while the CNT where added using a side feeder located at $\mathrm{L} / \mathrm{D}$ of 24 , after melting the polymer. The barrel and die were set to $200{ }^{\circ} \mathrm{C}$, the screw speed was $180 \mathrm{~min}^{-1}$ and the feed rate was $6 \mathrm{~kg} \mathrm{~h}^{-1}$. Most of the extruded strands were pelletized in-line after cooling, using a Pelltec SPP30 cutter (Coperion). Also, a few extruded strands were collected directly in order to measure their electrical conductivity.

Plaques with $160 \times 130 \times 3 \mathrm{~mm}$ were produced for all the tested compounds and controls by hot compression molding. For the PP and PP/CNT nanocomposites, the plaques were obtained at $210^{\circ} \mathrm{C}$ under $80 \mathrm{bar}$, pressed between two polytetrafluorethylene (PTFE) films. The PA12 and PA12/
CNT nanocomposites were previously dried at $80^{\circ} \mathrm{C}$ during $8 \mathrm{~h}$, and compression molded at $220^{\circ} \mathrm{C}$ under 80 bar. All the materials were cooled under pressure until reaching $80^{\circ} \mathrm{C}$ and then removed from the press. The plates where then cut into standardized specimens, according to the respective testing standards.

\subsection{Cable design and cable manufacture}

Figure 1a illustrates the typical design of a standard high voltage shielded cable. It comprises the metal conductor (1) that is insulated by an extruded polymer layer (2), which is encircled by a screen (a metallic braid) (3) and finally by an extruded jacket (4). In the present work, two alternative designs were considered. In a first attempt, the metallic braid was replaced by a nanocomposite tubing (Figure 1b). Subsquently (Figure 1c), a hybrid solution was also tested, in which both a ligher mettalic screen and a nanocomposite tubing were inserted between the insulation layer and the jacket.

The industrial extrusion line (supplied by Siebe Engineering, Germany) able to process either PP or PA12-based nancomposites, included a pay-off (to supply the insulated wire, which was produced beforehand by a conventional extrusion wire-coating operation), a single screw extruder equipped with a barrier-type screw, an extrusion head and die with adjustable wire-guide and die diameter (set to $230{ }^{\circ} \mathrm{C}$ ), two water cooling throughs approximately 5 and 100 meters long and set to $60^{\circ} \mathrm{C}$ and $23^{\circ} \mathrm{C}$, respectively, an on-line diameter sensor and a winder. The line operated at a speed of $60 \mathrm{~m} \mathrm{~min}^{-1}$. The jacket was applied in a subsequent conventional extrusion coating operation.

\subsection{Characterization}

The melt-volume flow rate (MVR) was measured with a Gottfert MI-3 tester according to method B of the ISO 1133:2005 standard, using a load of $2.16 \mathrm{~kg}$ at $230{ }^{\circ} \mathrm{C}$. PA12 and its nanocomposites were dried at $80{ }^{\circ} \mathrm{C}$ during $8 \mathrm{~h}$ and kept in a desiccator until tested.

Calcination tests were carried out by heating approximately $2 \mathrm{~g}$ of polymer and composite samples at $600^{\circ} \mathrm{C}$ during $2 \mathrm{~h}$ in air on a ThermoScientific M110 oven. The samples and residues were weighted on an Ohaus Pionner PA214 microbalance. Thermogravimetric analysis (TGA) was carried out on a TA Instruments Q800, heating the polymers and composites

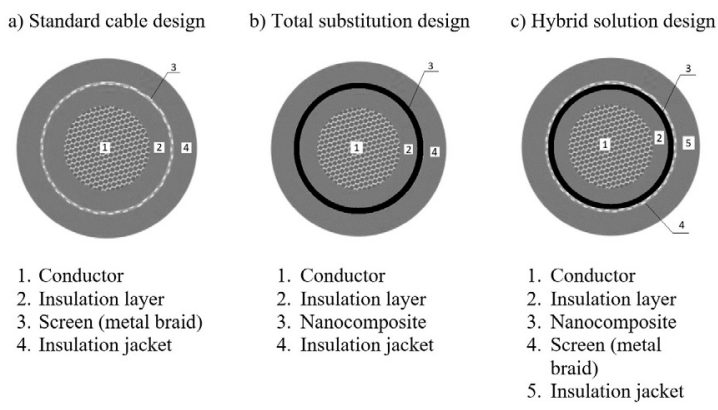

Figure 1. Schematic designs of a high voltage shielded cable: (a) standard cable design; (b) total substitution design; (c) hybrid solution design. 
under inert atmosphere (Ar) from $40{ }^{\circ} \mathrm{C}$ to $800{ }^{\circ} \mathrm{C}$ at a heating rate of $10^{\circ} \mathrm{C} \mathrm{min}^{-1}$.

Tensile testing was carried out on a Shimadzu AG-X universal testing equipment. The tensile strength was measured following the ISO 527-1/-2 standard with 5A shape dumbell bars, a load cell of $1 \mathrm{kN}$ and a displacement rate of $50 \mathrm{~mm}$ $\min ^{-1}$. The three-point bending test was performed according to the ISO 178 standard, with a load cell of $50 \mathrm{kN}$, dumbell bars with $40 \times 25 \times 2 \mathrm{~mm}$, a distance of $32 \mathrm{~mm}$ between supports, at $2 \mathrm{~mm} \mathrm{~min}^{-1}$.

Scanning electron microscopy (SEM) images were obtained with a JSM-6010LV SEM (JEOL, Japan), operating at $15 \mathrm{kV}$ accelerating voltage. Samples were cryo-fractured in liquid nitrogen and the resulting surfaces coated with $\mathrm{Au}$ to observe the transversal section of filaments.

A Keithley 2635B single channel sourcemeter was used to measure the volume electrical conductivity of the extruded strands, varying the potential from $-10 \mathrm{~V}$ to $10 \mathrm{~V}$ and measuring the corresponding current intensity. The average diameter of the PP and PA12 nanocomposite strands produced was $2.2 \mathrm{~mm}$ and $1.9 \mathrm{~mm}$, respectively. Cable components (1) and (3) (see Figure 1) were characterized electrically using a Wheatstone bridge.

The shielding effectiveness of the cables, expressed as attenuation $(\mathrm{dB})$, was measured according to the IEC 62153 standard. The set-up consisted of an electrical network analyser (Keysight E5071C, Keysight Technologies, USA) which included generator and receiver and a 3 meter long Rosenberger Bedea tube (Berkenhoff \& Drebes GmbH, Germany) that contained the test sample. Measurements were made at the most important frequencies $(100 \mathrm{MHz}$, $500 \mathrm{MHz}, 1 \mathrm{GHz}, 2 \mathrm{GHz}, 3 \mathrm{GHz}$ ).

Characterization of the cable heat resistance was carried out after exposure to $175^{\circ} \mathrm{C}$ during $240 \mathrm{~h}$. The electrical insulation along its length and the mechanical force required to bend the cable after exposure to heat were measured following the Original Equipment Manufacturer (OEM) standards.

\section{Results and Discussion}

The effective CNT content of the nanocomposites was assessed by TGA under inert atmosphere. Due to the very low apparent density of the CNT, small variations in their feed rate during composite production could affect the CNT concentration in the nanocomposite. Calcination tests were carried out to evaluate the content of inorganic fillers in the polymer grades used. Under calcination conditions, oxidative reactions develop leading to polymer (and additives) decomposition $^{[31]}$. CNT decomposition temperatures in air are usually in the range $390-730{ }^{\circ} \mathrm{C}$, depending mostly on their length and chemical structure ${ }^{[32]}$, and the residue is mostly formed by oxides of the CNT metal catalyst. Table 1 presents the weight $\%$ of the residue obtained in the calcination tests of all materials, as well as the residual weight obtained in the TGA tests, measured at $800{ }^{\circ} \mathrm{C}$. The results presented in Table 1 show that the residual weight obtained by calcination is very low for both polymers and their composites: below $0.08 \mathrm{wt} \%$ for the plain polymer and below $0.8 \mathrm{wt} \%$ for the composites with higher CNT content. Thus, the overall inorganic content is quite low. The differences observed may be induced by experimental factors such as the heterogeneous distribution of CNT along the extrudate, leading to a small shift in $\mathrm{wt} \%$.

Figure 2 shows the thermogravimetric plots obtained for the matrices and respective nanocomposites with highest CNT loading, i.e., $4 \mathrm{wt} \%$. Above $400{ }^{\circ} \mathrm{C}$ a large weight loss is observed for both polymer compounds, the composites presenting slightly higher thermal stability compared to the corresponding matrices ${ }^{[3,34]}$. For all samples, the polymer matrices registed higher weight loss than any of the nanocomposites, the larger residual weight obtained by TGA being associated to the CNT content. Since the CNT are stable under inert atmosphere up to temperatures near $3000{ }^{\circ} \mathrm{C}$, the residual weigth measured correlates to the nominal CNT incorporation levels. Therefore, these results validate the procedure adopted in this work for the preparation of the nanocomposites.

The dispersion of the CNT in the polymers during melt mixing is expected to induce an increase of the melt viscosity ${ }^{[26,28]}$. This is consistent with the increase observed in the melt pressure measured at the entrance of the shaping die during the compounding stage, presented in Figure 3. However, while for PP the incorporation of up to $4 \mathrm{wt} \%$ of CNT raises the melt pressure by approximately $9 \%$, for PA12 the raise in melt pressure is $62 \%$. This difference may relate to the CNT dispersion: at constant CNT content, higher dispersion of individual CNT throughout the composite induce a larger increase in the polymer melt viscosity. Thermo-mechanical degradation of PP and PA12 would lead to chain scission, and thus it would contribute to a decrease in viscosity, and thus in melt pressure. Since the effect is the opposite, the

Table 1. Residual weight $\%$ of the polymers and nanocomposites after calcination and thermogravimetric analysis under inert atmosphere.

\begin{tabular}{cccc}
\hline Matrix & CNT (wt. \%) & Calcination residual weight (\%) & TGA residual weight at 800 $^{\circ} \mathbf{C}\left(\mathbf{\%}^{\circ}\right)$ \\
\hline PP & 0 & $0.08 \pm 0.01$ & 0.22 \\
& 1 & $0.14 \pm 0.03$ & 1.21 \\
2 & $0.25 \pm 0.05$ & 2.22 \\
3 & $0.50 \pm 0.03$ & 3.24 \\
& 4 & $0.82 \pm 0.01$ & 4.21 \\
& 0 & $0.07 \pm 0.04$ & 0.18 \\
PA12 & 1 & $0.22 \pm 0.02$ & 1.06 \\
& 2 & $0.26 \pm 0.03$ & 2.09 \\
& 3 & $0.43 \pm 0.07$ & 3.07 \\
& 4 & $0.48 \pm 0.04$ & 4.11 \\
\hline
\end{tabular}




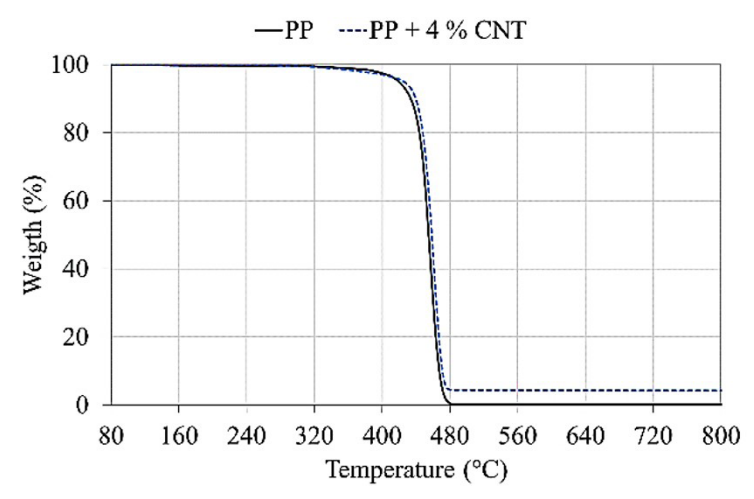

(a)

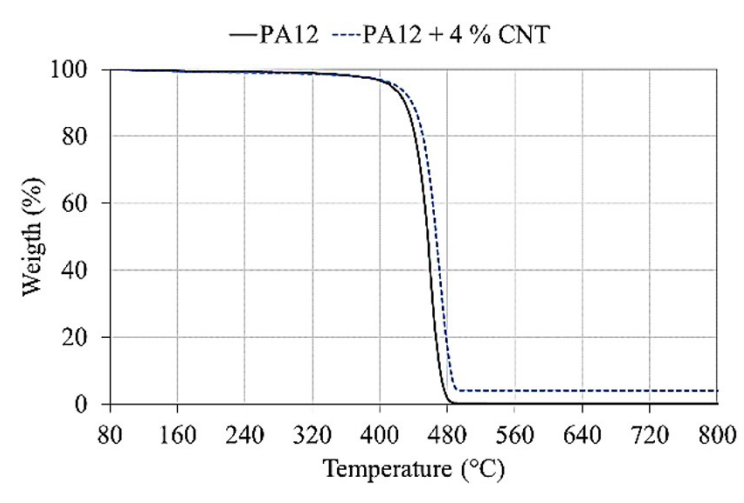

(b)

Figure 2. TGA plots for the polymers and their nanocomposites containing approximately 4 wt.\% CNT.

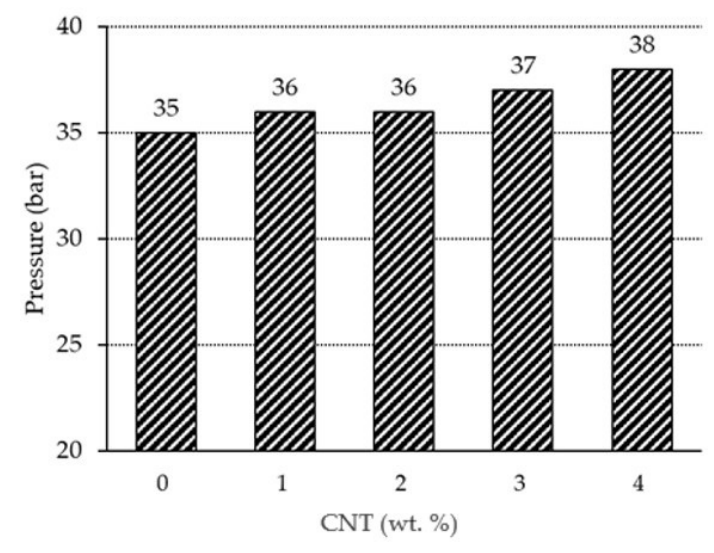

(a)

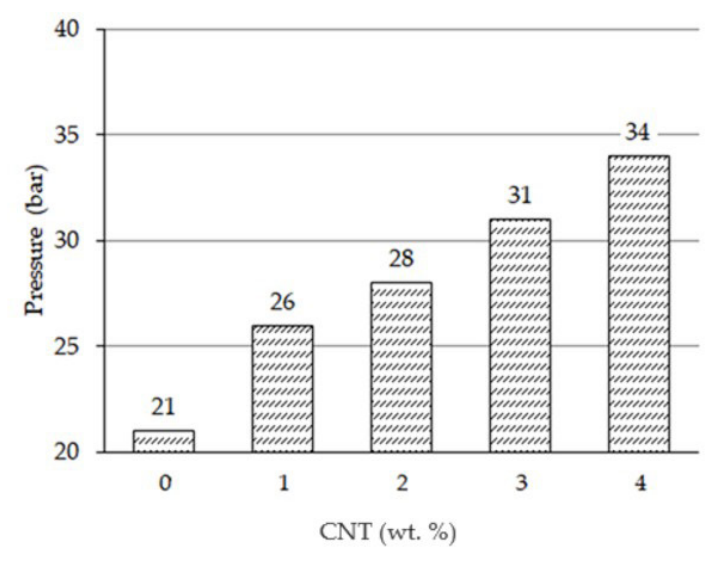

(b)

Figure 3. Melt pressure at the entrance of the die: (a) PP and PP/CNT nanocomposites; (b) PA12 and PA12/CNT nanocomposites.

effects observed should be essentially associated with the effective dispersion of the nanofiller.

Similar trends are observed for the MVR data (Figure 4). Interestingly, as the CNT content increases up to 4 wt. $\%$, the MVR decreases linearly for PP and its nanocomposites and logarithmically for PA12 at is nanocomposites. Equivalent drops in MVR have been reported ${ }^{[33]}$.

The effect of the addition of CNT on the tensile properties of the composites is depicted in Figure 5 and Table 2. As frequently reported in the literature ${ }^{[26,27]}$, the incorporation of CNT in a polymer matrix may not affect significantly the yield stress, but decreases the ductility. While the yield stress of the PA12/CNT nanocomposites tends to slightly increase relative to the polymer, the reverse is observed for the PP/CNT nanocomposites. This may result from differences in filler dispersion, as mentioned above, i.e., a less effective dispersion of CNT in the PP matrix resulting in the presence of larger CNT agglomerates.

Similar differences in behavior are observed for the flexural properties (Figure 6). The addition of CNT to PP has little effect on the flexural modulus and flexural strength

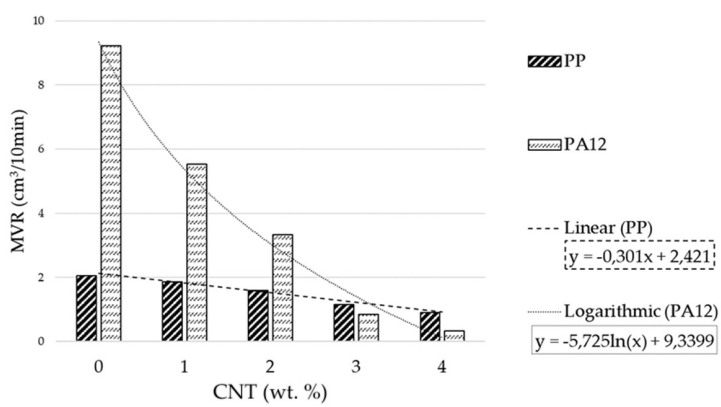

Figure 4. Effect of the addition of CNT to PP and PA12 on the MVR of the nanocomposites.

of PP, while for PA12 those properties increase up to $45 \%$ and $35 \%$, respectively, for composites with 4 wt. $\%$ CNT.

SEM images of the composites cross-section are presented in Figure 7 at two magnifications. The PP composites depict large CNT agglomerates at lower magnification. At higher magnification, the entangled CNT are observed, as well as 
the CNT agglomerate/polymer boundary, evidencing the absence of dispersed CNT beyond that boundary. Thus, the CNT form isolated islands of agglomerates in PP. Conversely, the CNT dispersed in PA12 may form a few small agglomerates (as depicted for PA12/3 wt $\%$ CNT at low magnification), however at higher magnification the individual CNT are observed across the whole matrix, forming a continuum. These observations confirm the good CNT dispersion achieved in PA12, contrasting with the presence of large agglomerates in PP.

Figure 8 presents the correlation between electrical conductivity and CNT concentration for the nanocomposites studied in this work. For PA12 electrical percolation was attained at CNT concentrations of approximately $3 \mathrm{wt} . \%$,
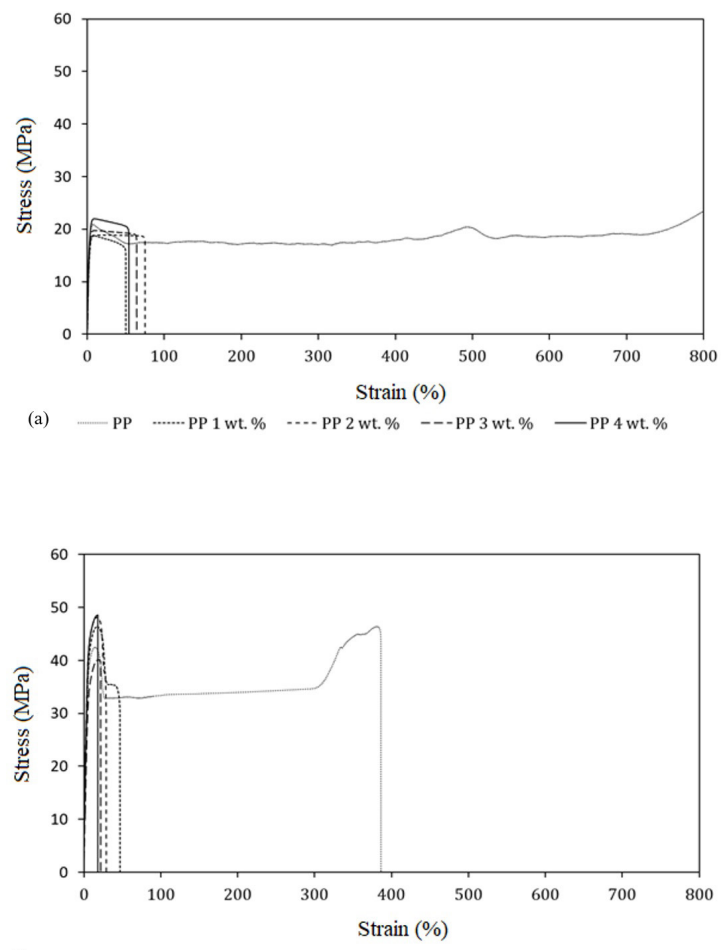

(b) - PA12 -.-...-PA12 1 wt. \% -..- PA12 2 wt. \% ---PA12 3 wt. \% —PP12 4 wt. \%

Figure 5. Tensile behaviour: stress-strain of (a) PP/CNT and (b) PA12/CNT nanocomposites. which agrees well with the values reported in the literature ${ }^{[15,35]}$. The electrical conductivity increased from $9.4 \times 10^{-7} \mathrm{~S} \mathrm{~m}^{-1}$ for the polymer to $3.52 \times 10^{-3} \mathrm{~S} \mathrm{~m}^{-1}$ for the PA12/4 wt.\% CNT nanocomposite. Conversely, no electrical percolation was reached for PP nanocomposites within the range of CNT addition studied. This result is in line with the previous considerations about the limited dispersion achieved.

Considering the results obtained for the electrical conductivity and mechanical reinforcement, the PA12/4 wt.\% CNT nanocomposite was selected as a potential candidate to replace the metallic braid integrated in standard high voltage shielded cables. The new cable (Figure 1b) was produced and its properties were compared with those of an equivalent standard cable. A weight reduction of $20 \%$ and an increase in production speed of one order of magnitude relative to the standard cable were attained. These are paramount competitiveness factors in the cable industry. Also, the thermal resistance of the two cables, expressed as the bending force after thermal ageing, was similar $(7 \mathrm{~N})$. However, while the electrical resistance of the conductor was the same in both cases, the resistance of the screen of the new cable was higher and could not be measured with the standard testing equipment, thus making it unsuitable to most automotive applications. Alternatively, a cable containing a hybrid screen, i.e., consisting of an inner nanocomposite tube enclosed in a loose metallic braid, was also manufactured (Figure 1c). This solution yielded a weight saving of $4 \%$ and a higher bending force $(11 \mathrm{~N})$ relative to the conventional cable. Figure 9 presents the shield effectiveness of the three types of cables manufactured in this study (Figure 1). While the standard cable exhibits an essentially frequency independent effectiveness, the new solutions show a tendency for a decrease with increasing frequency. However, the hybrid solution exhibits the highest effectiveness throughout the entire frequency range, which makes it appropriate for the applications under study. It is difficult to confront these results with data reported in the literature, since the latter were obtained at a higher frequency range $(8-13 \mathrm{GHz}$ in comparison to $0.001-3 \mathrm{GHz}$ adopted in this work) and for much thicker samples ${ }^{[36-38]}$. Anyway, for nanocpmposites containing $5 \mathrm{wt} \%$ of CNT, the measured values of shield efficiency were of the order of $|30| \mathrm{dB}^{[37]}$.

Table 2. Tensile properties of PP, PP/CNT, PA12 and PA12/CNT nanocomposites.

\begin{tabular}{|c|c|c|c|c|c|c|}
\hline Matrix & (\% CNT) & E (MPa) & $\sigma_{\mathrm{s}}(\mathrm{MPa})$ & $\varepsilon_{\mathrm{S}}(\%)$ & $\sigma_{\mathrm{B}}(\mathrm{MPa})$ & $\varepsilon_{\mathrm{B}}(\%)$ \\
\hline \multirow[t]{5}{*}{$\mathrm{PP}$} & 0 & $656 \pm 84$ & $23 \pm 0.6$ & $12 \pm 1.9$ & $-*$ & $-*$ \\
\hline & 1 & $633 \pm 29$ & $22 \pm 0.5$ & $10 \pm 2.5$ & $22 \pm 0.7$ & $62 \pm 9$ \\
\hline & 2 & $600 \pm 37$ & $19 \pm 0.3$ & $13 \pm 1.2$ & $20 \pm 0.5$ & $75 \pm 5$ \\
\hline & 3 & $588 \pm 26$ & $20 \pm 0.1$ & $13 \pm 1.1$ & $39 \pm 0.3$ & $64 \pm 5$ \\
\hline & 4 & $617 \pm 42$ & $22 \pm 0.3$ & $9 \pm 0.9$ & $42 \pm 0.4$ & $52 \pm 8$ \\
\hline \multirow[t]{5}{*}{ PA12 } & 0 & $672 \pm 41$ & $43 \pm 0.5$ & $19 \pm 1.2$ & $46 \pm 2.3$ & $386 \pm 8$ \\
\hline & 1 & $713 \pm 71$ & $47 \pm 0.6$ & $18 \pm 1.5$ & $40 \pm 3.1$ & $46 \pm 4$ \\
\hline & 2 & $744 \pm 32$ & $48 \pm 1.4$ & $16 \pm 1.1$ & $38 \pm 1.2$ & $30 \pm 5$ \\
\hline & 3 & $758 \pm 57$ & - & - & $41 \pm 0.9$ & $21 \pm 3$ \\
\hline & 4 & $787 \pm 72$ & - & - & $48 \pm 1.2$ & $18 \pm 4$ \\
\hline
\end{tabular}

*No break at $800 \%$. 


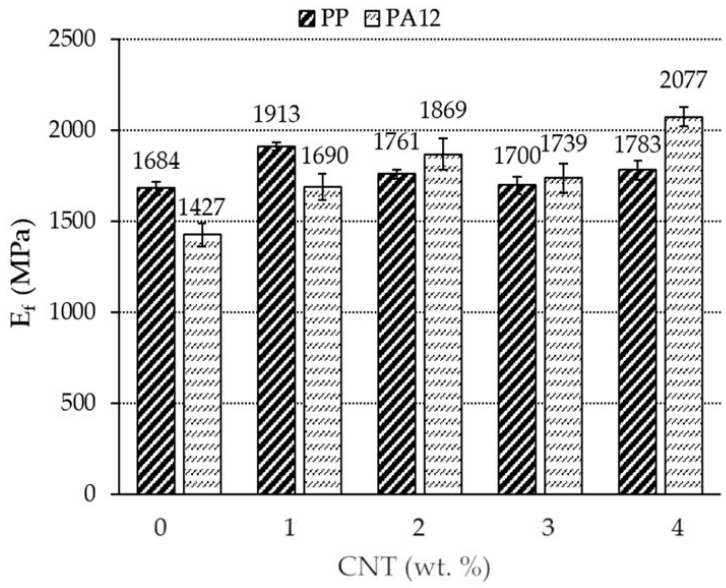

(a)

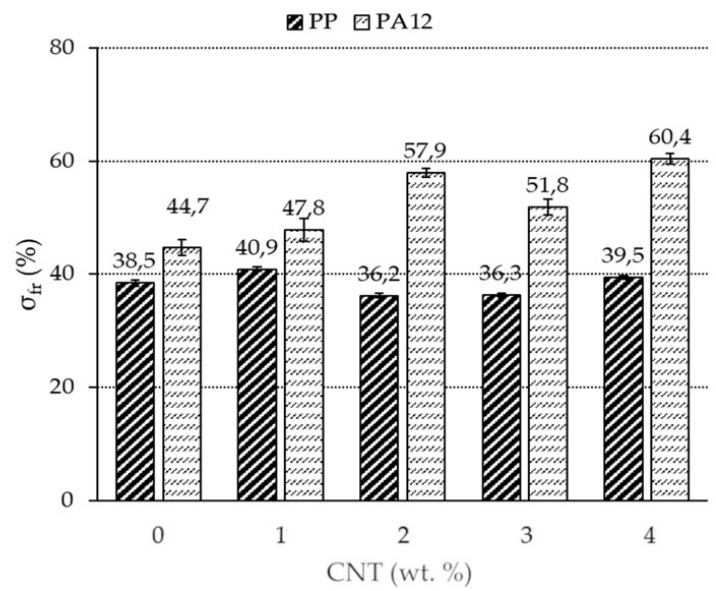

(b)

Figure 6. Flexural properties: (a) flexural modulus and (b) flexural strength of PP and PA12 composites.

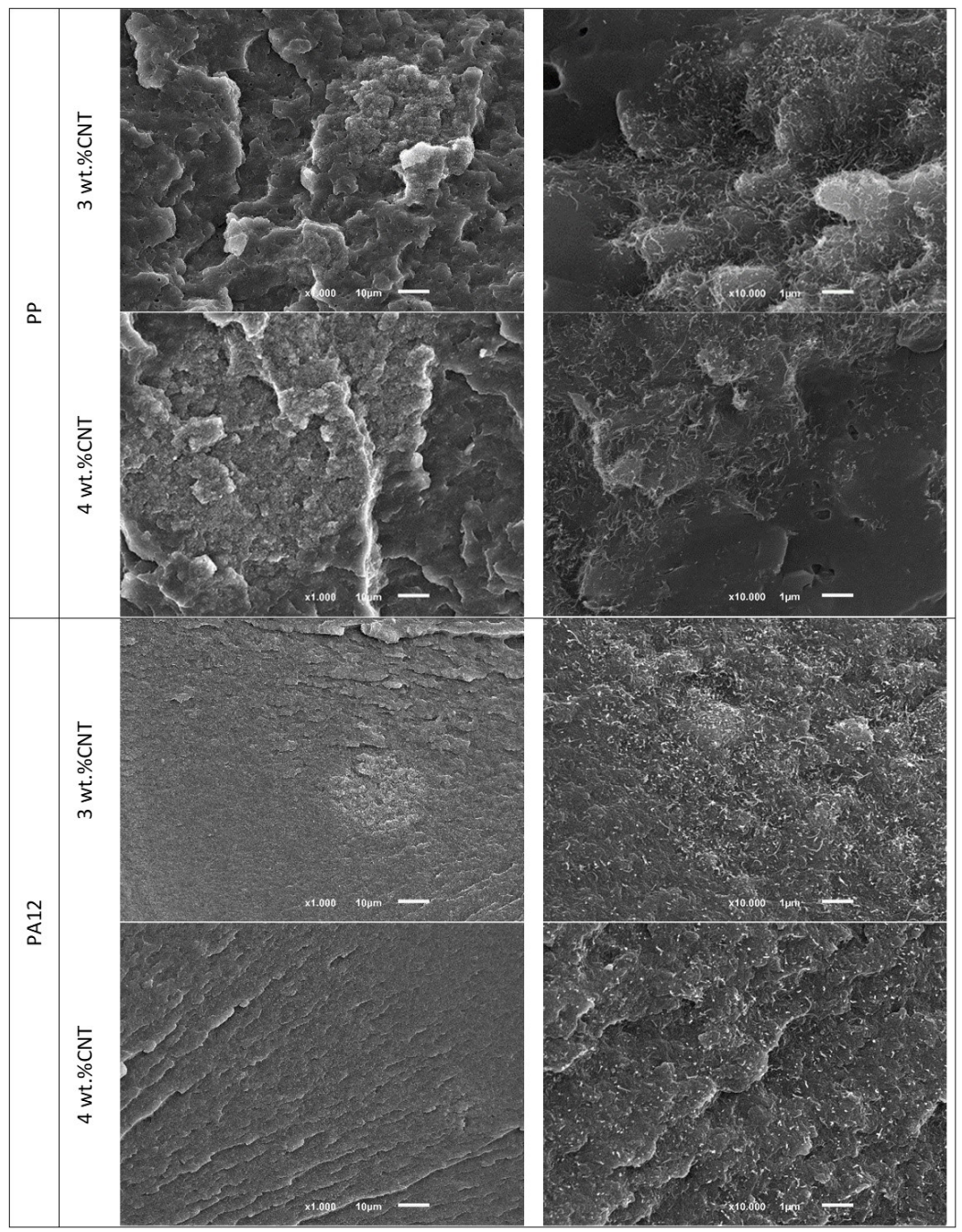

Figure 7. SEM images of PP and PA12 composites cross section. On the left column the scale bar represents $10 \mu \mathrm{m}$ and on the right column $1 \mu \mathrm{m}$. 


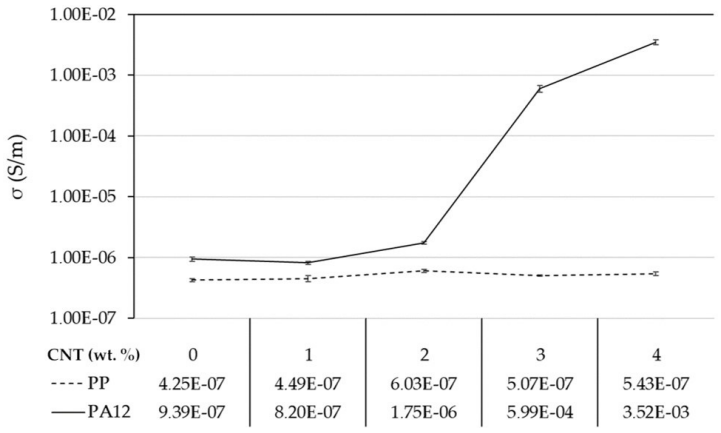

Figure 8. Electrical conductivity of PP and PA12 and corresponding nanocomposites.

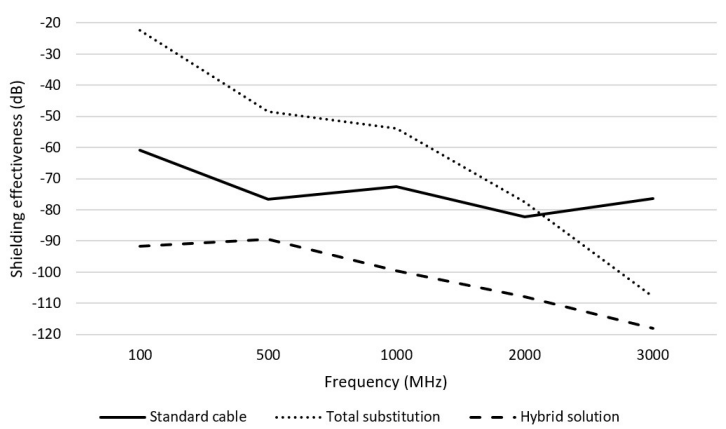

Figure 9. Shielding effectiveness (at 5 different frequencies) of the standard cable, cable with nanocomposite screen and cable with hybrid screen.

\section{Conclusions}

This work investigated the possibility of replacing the metallic screen of a high voltage automotive cable with a polymer/carbon nanotube (CNT) nanocomposite, in order to save weight. The study was carried out employing commercial materials, using conventional processing equipment in a production environment, and following the relevant international standards.

Polypropylene and polyamide 12 compounds were tested as possible matrices, and compositions up to $4 \mathrm{CNT}$ weight $\%$ were prepared and characterized. The PA $12 / C N T$ nanocomposites presented better performance, due to the poor dispersion of the CNT in the PP matrix as evidenced by SEM analysis of fractured cross-sections. The addition of CNT to PA12 caused a steady increase in melt viscosity, as inferred from melt pressure at the die and MVR data, but without affecting its processability. A moderate mechanical reinforcement effect was also observed in terms of tensile and flexural resistance. Electrical percolation was attained at CNT concentrations around $3 \mathrm{wt} . \%$, which is an excellent result when taking into consideration that compounding was performed by melt mixing and under practical production conditions. Consequently, a high voltage cable was manufactured with a screen made of a PA12/4 wt.\% CNT nanocomposite. This cable evidenced good mechanical/thermal performance, but insufficient electrical conductivity to most automotive applications. Therefore, an alternative design of a cable containg a screen consisting of a nanocomposite tube and a loose metallic braid was tested. This novel solution showed excellent shielding effectiveness.

Therefore, this investigation demonstrated that it is possible and practical to replace the metallic screen of conventional automotive high voltage cables by a nanocomposite solution, or a hybrid nanocomposite/metal solution, depending on the specific requirements of the application, enabling weight savings of the order of 4 to $20 \%$.

\section{Acknowledgements}

Funding by Operational Programme for Competitiveness and Internationalisation (COMPETE 2020), under the PORTUGAL 2020 Partnership Agreement, through the European Regional Development Fund (ERDF) to the NanoCCAb project is gratefully acknowledged. MCP and JAC thank the support of the Portuguese Foundation for Science and Technology (FCT) through the National Funds References UIDB/05256/2020 and UIDP/05256/2020.

\section{References}

1. International Cable Federation - ICF. (2015). Trends in automotive wiring. Austria: ICF.

2. WardsAuto. (2017). Auto engineers see future CAFE rules easing. Southfield, MI: WardsAuto Group.

3. Community Research and Development Information Service - CORDIS. (2017). Ultra conductive copper-carbon nanotube wire. Cambridge, UK: CORDIS.

4. Advanced Industries. (2012). Lightweight, heavy impact. USA: McKinsey \& Company.

5. Berylls Strategy Advisors. (2016). Automotive lightweight: heavy impact. In Economic Symposium. Austria.

6. European Comission. (2014). Strategy for reducing Heavy-Duty Vehicles fuel consumption and $\mathrm{CO}_{2}$ emissions - COM(2014)285. Belgium: European Comission.

7. International Council On Clean Transportat - ICCT. (2016). 2020-2030 $\mathrm{CO}_{2}$ standards for new cars and light-commercial vehicles in the European Union. Brussels: ICCT.

8. International Council On Clean Transportat - ICCT. (2017). Lightweighting technology developments. USA: ICCT.

9. European Environment Agency - EEA. (2020). Monitoring $\mathrm{CO}_{2}$ emissions from passenger cars and vans in 2018. Luxembourg: EEA.

10. Lekawa-Raus, A., Patmore, J., Kurzepa, L., Bulmer, J., \& Koziol, K. (2014). Electrical properties of carbon nanotube based fibers and their future use in electrical wiring. Advanced Functional Materials, 24(24), 3661-3682. http://dx.doi. org/10.1002/adfm.201303716.

11. Mittal, V., Kim, J. K., \& Pal, K. (2011). Recent advances in elastomeric nanocomposites. London: Springer. http://dx.doi. org/10.1007/978-3-642-15787-5.

12. Popov, V. N. (2004). Carbon nanotubes: properties and application. Materials Science and Engineering R Reports, 43(3), 61-102. http://dx.doi.org/10.1016/j.mser.2003.10.001.

13. Ali, M. N., Alamri, H., \& Wahab, A. (2015). Conductive nanocomposite fabrication by graphene enriched polypropylene master batch. International Journal of Engineering Development and Research, 3(4), 979-990. Retrieved in 2021, February 15, from https://www.ijedr.org/papers/IJEDR1504172.pdf

14. Du, F., Fischer, J. E., \& Winey, K. I. (2005). Effect of nanotube alignment on percolation conductivity in carbon nanotube/ 
polymer composites. American Physical Society, 72(12), 1-4. http://dx.doi.org/10.1103/PhysRevB.72.121404.

15. Bauhofer, W., \& Kovacs, J. Z. (2009). A review and analysis of electrical percolation in carbon nanotube polymer composites. Composites Science and Technology, 69(10), 1486-1498. http:// dx.doi.org/10.1016/j.compscitech.2008.06.018.

16. Bhattacharya, M. (2016). Polymer nanocomposites: a comparison between carbon nanotubes, graphene, and clay as nanofillers. Materials, 9(4), 262. http://dx.doi.org/10.3390/ma9040262. PMid:28773388.

17. Tanaka, K., \& Iijima, S. (2014). Carbon nanotubes and graphene. Kidlington: Elsevier.

18. Ma, P.-C., \& Kim, J.-K. (2011). Carbon nanotubes for polymer reinforcement. USA: CRC Press Taylor \& Francis Group. http://dx.doi.org/10.1201/b10795.

19. Das, D., \& Rahaman, H. (2015). Carbon nanotube and graphene nanoribbon interconnects. USA: CRC Press Taylor \& Francis Group.

20. Li, J., Ma, P. C., Sze, C. W., Kai, T. C., Tang, B. Z., \& Kim, J.-K. (2007). Percolation threshold of polymer nanocomposites containing graphite nanoplatelets and carbon nanotubes. In 16th International Conference on Composite Materials. Koyoto: International Conference On Composite Materials. Retrieved in 2021, February 15, from https://www.iccm-central.org/ Proceedings/ICCM16proceedings/contents/pdf/FriG/FrGM107ge_lij223410p.pdf

21. Socher, R., Krause, B., \& Pötschke, P. (2017). Effect of additives on MWCNT dispersion and electrical percolation in polyamide 12 composites. In AIP Conference Proceedings. Lyon: Polymer Processing Society. http://dx.doi.org/10.1063/1.5016703.

22. Paiva, M. C., \& Covas, J. A. (2016). Carbon nanofibres and nanotubes for composite applications. In S. Rana \& R. Fanguiro (Eds.), Fibrous and textile materials for composite applications (pp. 231-260). Singapore: Springer Nature. http:// dx.doi.org/10.1007/978-981-10-0234-2_7.

23. Hocke, H., \& Vitovsky, J. (2014). EP2810977A1. Munich: European Patent Office. Retrieved in 2021, February 15, from https://data.epo.org/gpi/EP2810977A1

24. Yan, D., Zhang, H. B., Jia, Y., Hu, J., Qi, X. Y., Zhang, Z., \& Yu, Z. Z. (2012). Improved electrical conductivity of polyamide 12/ graphene nanocomposites with maleated polyethylene-octene rubber prepared by melt compounding. ACS Applied Materials \& Interfaces, 4(9), 4740-4745. http://dx.doi.org/10.1021/ am301119b. PMid:22889067.

25. Socher, R., Krause, B., Hermasch, S., Wursche, R., \& Pötschke, P. (2011). Electrical and thermal properties of polyamide 12 composites with hybrid fillers systems of multiwalled carbon nanotubes and carbon black. Composites Science and Technology, 71(8), 1053-1059. http://dx.doi.org/10.1016/j. compscitech.2011.03.004.

26. Jamali, S., Paiva, M. C., \& Covas, J. A. (2013). Dispersion and re-agglomeration phenomena during melt mixing of polypropylene with multi-wall carbon nanotubes. Polymer Testing, 32(4), 701707. http://dx.doi.org/10.1016/j.polymertesting.2013.03.005.

27. Vilaverde, C., Santos, R. M., Paiva, M. C., \& Covas, J. A. (2015). Dispersion and re-agglomeration of graphite nanoplates in polypropylene melts under controlled flow conditions. Composites. Part A, Applied Science and Manufacturing, 78, 143-151. http://dx.doi.org/10.1016/j.compositesa.2015.08.010.
28. Rodrigues, P., Santos, R. M., Paiva, M. C., \& Covas, J. A. (2017). Development of dispersion during compounding and extrusion of polypropylene/graphite nanoplates composites. International Polymer Processing, 32(5), 614-622. http:// dx.doi.org/10.3139/217.3485.

29. Palacios-Aguilar, E., Bonilla-Rios, J., Sanchez-Fernandez, J. A., Vargas-Martinez, A., Lozoya-Santos, J. J., \& RamırezMendoza, R. (2020). Comparing the elasticity of the melt and electrical conductivity of the solid of PP-HDPE copolymer CNT composites obtained by direct compounding versus dilution of a PP masterbatch. Journal of Intelligent Material Systems and Structures, 32(10), 1105-1115. http://dx.doi. org/10.1177/1045389X20969836.

30. Socher, R., Krause, B., Boldt, R., Hermasch, S. A., Wursche, R., \& Pötschke, P. (2011). Melt mixed nano composites of PA12 with MWNTs: influence of MWNT and matrix properties on macrodispersion and electrical properties. Composites Science and Technology, 71(3), 306-314. http://dx.doi.org/10.1016/j. compscitech.2010.11.015.

31. Witkowski, A., Stec, A. A., \& Hull, T. R. (2015). Thermal decomposition of polymeric materials. In M. J. Hurley (Eds.), SFPE handbook of fire protection (pp. 167-254). New York: Society of Fire Protection Engineers. http://dx.doi. org/10.1007/978-1-4939-2565-0.

32. Buzarovska, A., Stefov, V., Najdoski, M., \& Bogoeva-Gaceva, G. (2015). Thermal analysis of multi-walled carbon nanotubes material obtained by catalytic pyrolysis of polyethylene. Macedonian Journal of Chemistry and Chemical Engineering, 34(2), 373-379. http://dx.doi.org/10.20450/mjcce.2015.620.

33. Song, P., Cao, Z., Cai, Y., Zhao, L., Fang, Z., \& Fu, S. (2011). Fabrication of exfoliated graphene-based polypropylene nanocomposites with enhanced mechanical and thermal properties. Polymer, 52(18), 4001-4010. http://dx.doi. org/10.1016/j.polymer.2011.06.045.

34. Yetgin, S. H. (2019). Effect of multi walled carbon nanotube on mechanical, thermal and rheological properties of polypropylene. Journal of Materials Research and Technology, 8(5), 47254735. http://dx.doi.org/10.1016/j.jmrt.2019.08.018.

35. Prashantha, K., Soulestin, J., Lacrampe, M. F., Claes, M., Dupin, G., \& Krawczak, P. (2008). Multi-walled carbon nanotube filled polypropylene nanocomposites based on masterbatch route: improvement of dispersion and mechanical properties through PP-g-MA addition. Express Polymer Letters, 2(10), 735-745. http://dx.doi.org/10.3144/expresspolymlett.2008.87.

36. Radi, H., \& Rasmussen, J. O. (2013). Principles of physics. USA: Springer. http://dx.doi.org/10.1007/978-3-642-23026-4.

37. Al-Saleh, M. H., Saadeh, W. H., \& Sundararaj, U. (2013). EMI shielding effectiveness of carbon based nanostructured polymeric materials: a comparative study. Carbon, 60, 146156. http://dx.doi.org/10.1016/j.carbon.2013.04.008.

38. Poothanari, M. A., Pottathara, Y. B., \& Thomas, S. (2019). Carbon nanostructures for electromagnetic shielding applications. In S. Thomas, Y. Grohens \& Y. B. Pottathara(Eds.), Industrial applications of nanomaterials: micro and nano technologies. Amsterdam: Elsevier. http://dx.doi.org/10.1016/B978-0-12-815749-7.00008-6.

Received: Feb. 15, 2021

Revised: July 16, 2021

Accepted: Aug. 09, 2021 